\title{
Influence of the resin cement thickness on the fatigue failure loads of CAD/CAM feldspathic crowns
}

\author{
Liliana Gressler May ${ }^{a, *}$, J. Robert Kelly ${ }^{b}$, Marco Antonio Bottino ${ }^{c}$, Tom Hill ${ }^{d}$ \\ a Restorative Dentistry Department, Federal University of Santa Maria, Santa Maria, RS, Brazil \\ ${ }^{\mathrm{b}}$ Reconstructive Sciences, University of Connecticut Health Center, Farmington, CT, USA \\ c Department of Dental Materials and Prosthodontics, São Paulo State University, São José dos Campos, Brazil \\ d Ivoclar/Vivadent Inc., Division for Research, Amherst, NY, USA
}

\section{A R T I C L E I N F O}

Article history:

Received 13 November 2014

Received in revised form

10 February 2015

Accepted 28 April 2015

Keywords:

Ceramic

Crowns

Cement thickness

Failure load

Fatigue

\begin{abstract}
A B S T R A C T
Objectives. to evaluate the influence of the occlusal resin cement thickness on the cyclic loads-to-failure of feldspathic crowns and to compare the results to data from monotonic tests. A large range of cement thickness $(50 \mu \mathrm{m}$ and $500 \mu \mathrm{m})$ was tested, in order to better measure the influence of this variable.

Methods. Feldspathic ceramic crowns (Vita Mark II blocks, Vita Zahnfabrik) were bonded to dentin analog dies (G10 (NEMA grade G10, International Paper), with occlusal resin cement thicknesses of $50 \mu \mathrm{m}$ and $500 \mu \mathrm{m}$ (Multilink Automix, Ivoclar). The dies were prepared with microchannels for water transport to the cement layer. After $96-\mathrm{h}$ water storage, the specimens $(n=20)$ were submitted to cyclic loads $(500,000$ cycles at $20 \mathrm{~Hz}$; initial maximum load $=40 \%$ of monotonic load, from previous data) following a staircase sensitivity design (step size $=25 \mathrm{~N}$ ). Failure loads at 500,000 cycles were compared to monotonic failure loads (from a previous study with specimens produced by the same author, using the same materials, specimen configuration and cementation protocol).

Results. Crowns with an occlusal cement layer of $50 \mu \mathrm{m}$ were more resistant than those cemented with $500 \mu \mathrm{m}(246.4 \pm 22.9 \mathrm{~N}$ vs. $158.9 \pm 22.9 \mathrm{~N})$, under wet cyclic testing conditions $(p<0.001)$. The fatigue failure loads were reduced compared to monotonic loads: to $37 \%$ of monotonic for $50 \mu \mathrm{m}$; to $53 \%$ of monotonic for $500 \mu \mathrm{m}$.

Significance. An occlusal cement thickness of $50 \mu \mathrm{m}$ was more favorable for the structural performance of feldspathic crowns than was $500 \mu \mathrm{m}$. Cyclic fatigue reduced failure loads well below those found under monotonic loading.
\end{abstract}

(c) 2015 Academy of Dental Materials. Published by Elsevier Ltd. All rights reserved.

\footnotetext{
* Corresponding author at: Rua Floriano Peixoto 1184, CEP 97015-372, Santa Maria, RS, Brazil. Tel.: +55 5532209290 ; fax: +55 5532209290.

E-mail address: liligmay@gmail.com (L.G. May).
} 


\section{Introduction}

The effect of the resin cement thickness on the durability of ceramic restorations has not been widely investigated and until recently it has been considered a factor of minor influence [1,2]. However, Scherrer et al. [3] tested feldspathic ceramic tabs cemented to composite with resin cement thicknesses ranging from $26 \pm 11 \mu \mathrm{m}$ to $297 \pm 48 \mu \mathrm{m}$ and observed a gradual decrease of the fracture strength that became statistically significant at a cement thickness of $300 \mu \mathrm{m}$.

Many studies have reported that the occlusal thickness of cement under CAD/CAM ceramic crowns can vary widely. Colpani et al. [4] found a narrow space in the occlusal area of CAD/CAM zirconia copings (45.2 and $55.2 \mu \mathrm{m}$ ). An average occlusal space centered on $100-250 \mu \mathrm{m}$ is quite common in the recent literature [5-12]. However, variable occlusal misfits, of $24 \mu \mathrm{m}$ and $634 \mu \mathrm{m}$ beneath cusp tips and central fossa [13] and as large as $1316 \mu \mathrm{m}$ [14], have also been reported.

May et al. [15] showed a significant influence of the occlusal cement thickness on the failure loads of feldspathic ceramic crowns, either under bonded or non-bonded conditions. This study took into account the polymerization shrinkage of the cement layer, demonstrating that this phenomenon can be directly related to the gap formation and to the increase of tensile stresses on the crown, resulting in decreasing failure loads over occlusal cement thickness ranging from 50 to $500 \mu \mathrm{m}$.

However, according to Feilzer et al. [16] water sorption can relieve stresses generated by shrinkage polymerization in hydrophilic composite, such as those based on BisGMA/TEGDMA or UDMA. The dentin underneath the restoration is a source of water and its sorption can actually surpass the neutral condition and could be responsible for some expansion stresses in the adhesive interface. The sorption rate is dependent on the nature of the resin, the kind/amount of fillers, adhesion matrix/filler, the resin volume and its accessibility to water [17]. Alrahlah et al. [18] found from 0.58 to $2.26 \%$ of hygroscopic volumetric expansion in $2 \mathrm{~mm}$ disks of eight resin composites. Equilibrium was attained by 60 days. For the lowest filler loading, the volumetric expansion reached around $56 \%$ of the final value by 7 days.

Cyclic mechanical loads were applied under wet conditions to simulate the use of the ceramic restorations and the damage accumulation that occurs clinically. In a wet environment, the water sorption by the cement layer may work to reverse the negative influence of the polymerization shrinkage. Cyclic loads can also lead to softening in brittle polymers, such as the dental cements. Damage accumulation involving, for example microcracking ahead of propagating cracks, can lead to modes of crack initiation and growth not seen under monotonic loads, either in cements or ceramics [19].

Thus the presence of water during the cyclic loading may allow the cement to expand by sorption [16] and also can act chemically at crack tips, assisting the phenomenon known as slow crack growth $[20,21]$, which decreases the strength of glasses and ceramics [22,23]. This phenomenon happens to all ceramics even with only a little bit of water as in atmospheric conditions.

The aims of this study were: (1) to evaluate the influence of the occlusal resin cement thickness $(50 \mu \mathrm{m}$ and $500 \mu \mathrm{m})$ on the failure loads of feldspathic crowns bonded to dentin analog dies using wet mechanical cyclic tests, and (2) to compare these results to monotonic data produced in a previous work, with specimens produced by the same operator, using the same materials, specimen configuration and cementation protocol. The range of thickness evaluated was chosen in order to have a better measurement of its effect. The null hypotheses were: (1) mean failure loads will not be influenced by the occlusal cement thickness; (2) wet mechanical cyclic testing will not reduce the failure loads in comparison to the monotonic testing, for both occlusal cement thickness, $50 \mu \mathrm{m}$ and $500 \mu \mathrm{m}$.

\section{Materials and methods}

\subsection{Specimen preparation}

Forty dentin analog dies (preparation height $=5.32$; internal angle radii $=0.5 \mathrm{~mm}$; axial wall convergence $=16^{\circ}$; cervical preparation depth $=1.2 \mathrm{~mm}$; round shoulder radii $=0.5 \mathrm{~mm}$ ) were machined from $11 \mathrm{~mm}$-diameter rods of an epoxy-glass cloth - G10 (NEMA grade G10, International Paper, Hampton, SC, USA). Five microchannels for water transport were made in the intaglio surface of each die (Fig. 1).

Crown patterns with occlusal cementation spaces of $50 \mu \mathrm{m}$ $(n=20)$ and $500 \mu \mathrm{m}(n=20)$, occlusal thickness of $1.5 \mathrm{~mm}$ and nearly $100 \mu \mathrm{m}$ of cementation space in the axial-walls were machined from aluminum. These patterns were scanned, imported to the CEREC in Lab CAD utility and duplicated by machining from Vita Mark II blocks (Vita Zahnfabrik, Germany). After machining, the crowns were tried onto their respective dies. When any binding was encountered in the axial walls, the dies were adjusted. This adjustment allowed every crown to reach the maximum seating at the margin so that the intended occlusal cement thickness was achieved. The occlusal spaces were checked in 2 crowns per group, using poly (vinyl siloxane) and the values were found to range between: $57 \mu \mathrm{m}$ and $85 \mu \mathrm{m}$ for the $50 \mu \mathrm{m}$ group; $505 \mu \mathrm{m}$ and $555 \mu \mathrm{m}$ for the $500 \mu \mathrm{m}$ group. Cement thicknesses were measured in all crowns following testing.

Crowns were finished on their occlusal surface (silicon carbide grit \# 600), resulting in final occlusal thickness of $1.4 \mathrm{~mm}$. The internal crown surface was acid etched with $9 \%$ HF (Porcelain Etch, Ultradent products Inc., South Jordan, Utah, USA, batch \# B461M) for $60 \mathrm{~s}$, washed for $15 \mathrm{~s}$ and ultra-sonic cleaned for $1 \mathrm{~min}$, in order to remove the acid residues off the surface.

The dies were cleaned in an ultra-sonic bath (3 min). After drying they had their microchannels occluded with accessory gutta-percha points (\# 35) (Fig. 1a and b) and their surface treated with a primer mixture (Primer A and Primer B, Ivoclar, Liechstenstein).

Resin cement (Multilink Automix, (Ivoclar Vivadent, Schaan, Liechtenstein, batch \#41970) was applied through an automix tip to the occlusal surface of the dies and the crowns were seated under a load of $4.6 \mathrm{~N}$. Excess cement was removed following $2 \mathrm{~s}$ of light curing from two opposite directions at the margin. Light curing was applied to two opposite axial walls for $20 \mathrm{~s}$ each. Following that, the weight was removed and 

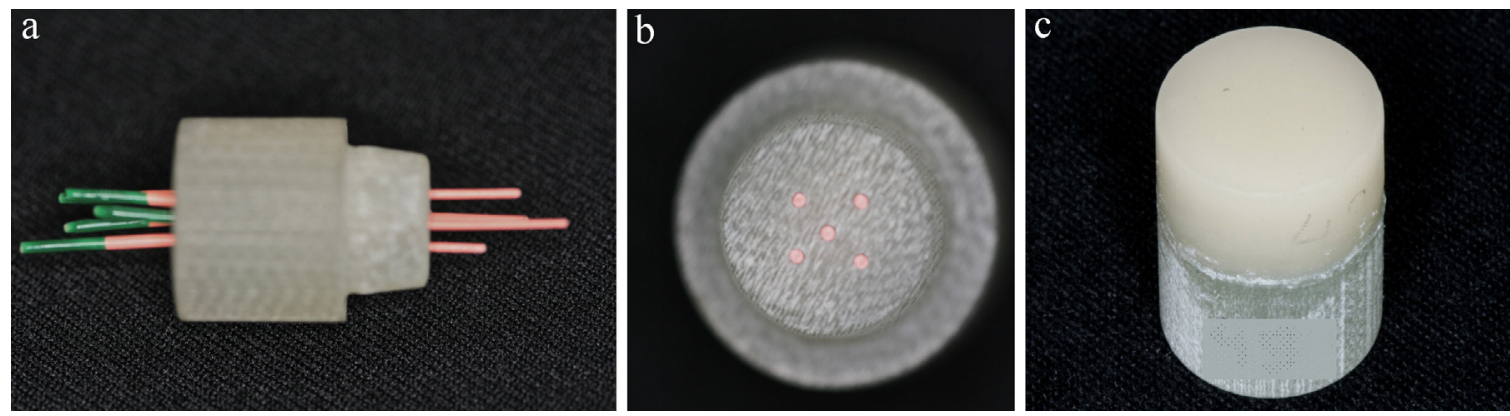

Fig. 1 - Illustrations showing of a G10 die being prepared for cementation prior the cyclic loading. (a and b) Microchannels (for water communication) were sealed using gutta-percha points in order to avoid cement obturation during cementation. Before storage and cycling they were removed; (c) specimen after crown cementation.

curing light was applied for 20 s to the occlusal surface of the crown.

After cementation, the gutta-percha points were removed and the specimens were stored in distilled water $96 \mathrm{~h}$. In order to enhance water flow through the microchannels to the cement layer, a cotton fiber piece was placed inside the die and water was injected with a syringe, eliminating air bubbles within the die.

\subsection{Wet cyclic loading test}

After $96 \mathrm{~h}$ of water storage, each specimen (Fig. 1c) was placed in a wet cycling chamber (Fig. 2). The chamber had the inclination and lateral displacement adjusted, so that the specimen was centrally and perpendicularly loaded, using a $2 \mathrm{~mm}$ diameter piston made from the G10 epoxy-glass cloth. A $110 \mu \mathrm{m}$ thick polyethylene strip was placed between the ceramic and the indenter (MTS 858 Mini Bionix II; MTS Systems Corp, Edens Prairie, Minn). Cyclic failure loads $(500,000$ cycles at $20 \mathrm{~Hz}$ ) were evaluated using the staircase sensitivity design [24]. Initial loads were based on the monotonic results [15], anticipating that the cyclic loads would be around $40 \%$ of the monotonic failure loads. A step size load of $25 \mathrm{~N}$ was applied up or down to the next specimen, according to the survival or failure of the previous specimen.

\subsection{Data analysis}

After the cyclic test, all crowns were examined for contact surface damage (e.g., Hertzian cone cracks). Data from crowns demonstrating contact damage were excluded from statistical calculation. The means and standard deviation were calculated by the staircase sensitive statistical method [24].

After the cyclic testing all crowns were embedded in acrylic resin. Twenty-four hours later, they were sectioned in two halves, perpendicularly to the direction of the crack. The thickness of the ceramic and the cement under the loading indenter were measured in a microscope (Gaertner, Gaertner Scientific Corporation, Chicago, USA). Mean wet cyclic failure loads were normalized to a ceramic thickness of $1.65 \mathrm{~mm}$ (Eq. (1)), in order to compare them to monotonic data from an earlier study [15], in which the specimens with the same configuration were produced using the same method by the same author.

normalized $L=$ experimental $L\left(\frac{1.65}{\text { real }^{T}}\right)^{2}$

where $L$ is load $(\mathrm{N})$; $T$ is ceramic thickness $(\mathrm{mm})$.

Means were submitted to the analysis of variance (significance level of $5 \%$ ).

\section{Results}

Figs. 3 and 4 show the up-and-down loading values from the staircase sensitive experimental design, according to whether the crowns failed or survived after 500,000 cycles in water. Cyclic loads-to-failure of feldspathic CAD/CAM crowns decreased with the increasing resin cement thickness (Table 1; Fig. 5). Significant differences were found between the groups (ANOVA, $p<0.001$ ), indicating that crowns with an
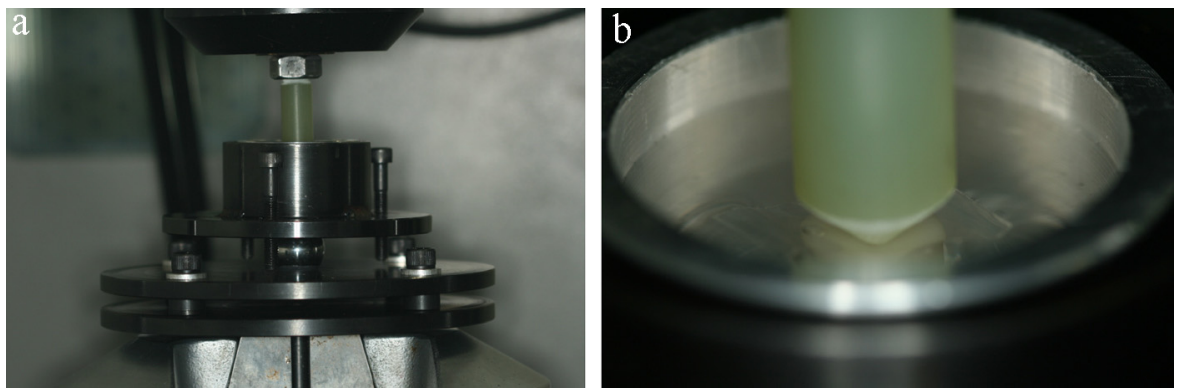

Fig. 2 - Illustration of the wet cycling chamber (a) specimen being loaded in the test machine; (b) close view of a specimen, inside the water chamber. 


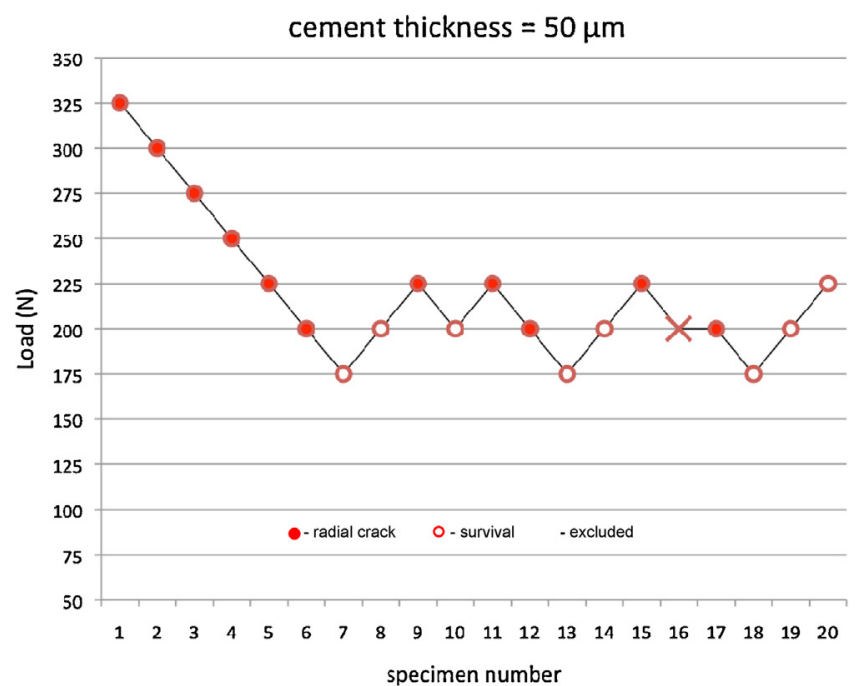

Fig. 3 - Staircase sensitivity test results during wet mechanical cycling $(500,000$ cycles) of CAD/CAM feldspathic ceramic crowns bonded to $50 \mu \mathrm{m}$ of occlusal resin cement thickness.

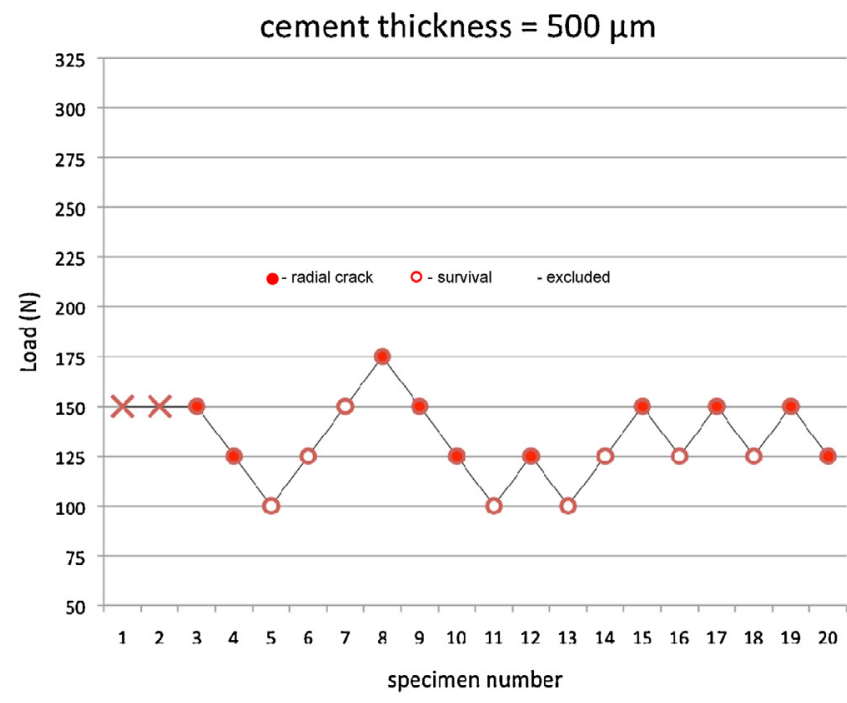

Fig. 4 - Staircase sensitivity test events during wet mechanical cycling (500,000 cycles) of CAD/CAM feldspathic ceramic crowns bonded to $500 \mu \mathrm{m}$ of occlusal resin cement thickness.

Table 1 - Mean failure loads (standard deviation - SD) of CAD/CAM feldspathic crowns from wet cyclic fatigue testing (wc $L$ ) and dry monotonic testing $\left(\mathrm{md}^{\mathrm{L}} \mathrm{L}\right.$ ) for two different occlusal resin cement thicknesses (50 and $\mathbf{5 0 0} \boldsymbol{\mu m})$.

\begin{tabular}{lcc}
$\begin{array}{l}\text { Cement thickness } \\
(\mu \mathrm{m})\end{array}$ & $\left.{ }_{\text {wc }} \mathrm{(SD}\right)-\mathrm{N}^{\mathrm{a}}$ & $\begin{array}{c}\mathrm{md}^{L}(\mathrm{SD})-\mathrm{N}^{\mathrm{a}} \\
\text { from May et al. [15] }\end{array}$ \\
\hline 50 & $246.4(22.9)^{\mathrm{Ab}}$ & $673.5(88.4)$ \\
500 & $158.9(22.9)^{\mathrm{B}}$ & $300.6(41.57)$ \\
\hline a Values normalized for 1.65 mm of occlusal ceramic thickness. \\
b Different letters in the column indicate statistical difference \\
\multicolumn{2}{l}{ (Tukey 5\%). }
\end{tabular}

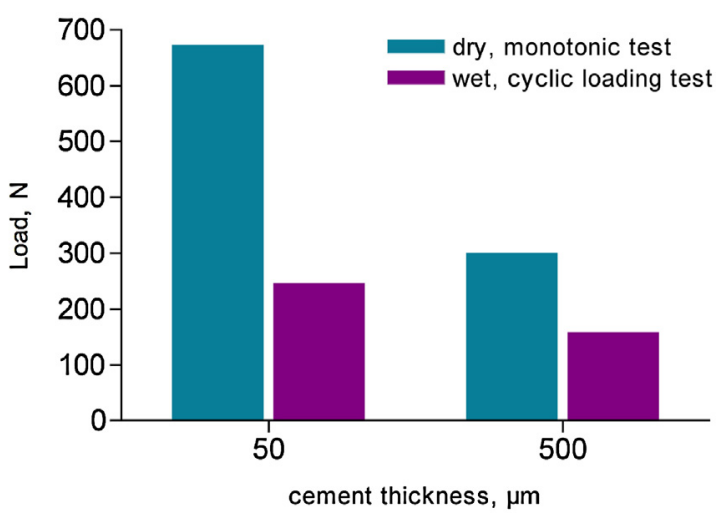

Fig. 5 - Dry monotonic (from May et al. [15]) and wet cyclic failure loads $(\mathrm{N})$ of CAD/CAM feldspathic ceramic crowns bonded to $50 \mu \mathrm{m}$ and $500 \mu \mathrm{m}$ of occlusal resin cement thickness.

occlusal cement layer of $50 \mu \mathrm{m}$ were more resistant than those cemented with $500 \mu \mathrm{m}$.

Data from May et al. [15] was included in Table 1, in order to allow the comparison between the loads to failure from monotonic dry testing and from wet cyclic loading. Monotonic failure loads decreased twice from crowns with $50 \mu \mathrm{m}$ to $500 \mu \mathrm{m}$ occlusal cement thickness. However, after the crowns were submitted to the wet cyclic loading, the difference between the thickness groups was less pronounced (Table 1 and Fig. 5).

The negative effect of the wet cyclic fatigue was larger for crowns with $50 \mu \mathrm{m}$ cement thickness (loads were reduced to $37 \%$ of the monotonic failure load) than for $500 \mu \mathrm{m}$ (loads reduced to $53 \%$ of the monotonic failure load).

\section{Discussion}

A "cushion" effect is expected to happen due to the presence of a low elastic modulus layer (cement) under a much stiffer material (ceramic crown), allowing a bending strain of the restoration under load, potentially leading to tensile fracture of the ceramic at the cementation surface [25]. The relatively low modulus of the resin cement $(6.3 \mathrm{GPa}$ for Multilink Automix) [26] compared to that of a glass-ceramic (64 GPa) [27], allows bending stresses when loading is applied. So theoretically, the thicker the cement under the crown the larger will be the deflection of the cement layer and the higher will be the stresses in the tensile surface of the crown at any given load. This was consistent with observations in both this and the previous study [15], in which the thicker cement at the occlusal face reduced the loads to fracture of the crowns.

Some FEA studies have shown small effect of cement thickness on the stresses in a crown. However, in these studies, the cement thickness was varied in a narrower range than the current study: 50-100 $\mu \mathrm{m}$ [1] and 80-100 $\mu \mathrm{m}$ [2]. Recent literature has shown that the mean values of occlusal misfit in CAD/CAM crowns can center around 100-250 $\mu \mathrm{m}$ [8-12]. In addition, the cement shrinkage was not considered in these simulations. On the other hand, May et al. [15] showed that the tensile 
stresses in bonded crowns were greatly affected by the polymerization shrinkage, as the occlusal cement layer becomes thicker (from 50 to $500 \mu \mathrm{m}$ ). In agreement, Hsueh et al. [28] found experimentally and by FEA, that increasing the adhesive interlayer thickness in brittle coatings (silicon/epoxy/glass) from 1 to $1000 \mu \mathrm{m}$ makes the critical load for initiating cracks decrease from around $1000 \mathrm{~N}$ to $250 \mathrm{~N}$.

Other authors have studied the relationship between cement thickness and the ceramic's fracture resistance. Sherrer et al. [3] did not find significant influence of the cement thickness on failure loads. Tuntiprawon et al. [29] reported a decrease in the load to fracture for increasing cement thickness. However, spherical indenters were used in these studies, which are known to cause cone-cracking, much more related to high stresses at the contact surface than to tensile stresses at the cementation surface of the ceramic $[23,30]$. Hence, these tests likely did not detect the influence of the occlusal cement layer on the ceramic resistance to sub-surface radial cracking as seen in clinical failure

One of the statistical designs used in fatigue studies of dental ceramics is the staircase method, which assumes that the data are normally distributed. The strength data of brittle materials typically fit in the Weibull distribution [31]. However, according to Danzer et al. [32], a Weibull distribution function has to be measured in at least 30 samples, which increases the costs for specimen preparation. Kelly et al. [23], studying fatigue protocol for cemented bilayered ceramics, obtained coefficients of variation of approximately $10 \%$ with a modest number of specimens $(\leq 20)$ in a staircase sensitivity test design. In addition, at a Weibull modulus of 3-4 (a likely value for etched dental porcelain) the Weibull and normal distributions are nearly identical. Therefore, the staircase method was chosen because of its viability and low variability.

The current study followed protocols in order to simulate clinical failures of ceramic crowns, with cracks starting from the cementation surface [23]. The majority of failures occurred as radial cracks, from the tensile side of the ceramic crown and not from contact damage on the loaded surface caused by the piston. This lack of contact damage is attributed to the use of a flat-end piston made from G10 and a plastic strip between piston and crown during the test. Undesired Hertzian cone cracks, caused by contact damage, happened in 3 specimens, only when abrupt piston displacement accidentally occurred during testing.

Dental ceramics have been shown to be stress-rate sensitive in the presence of water; that is, their strength is reduced the longer they are under load [23]. Water from the oral environment can be involved with breakage of metal-oxide bonds at the crack tip under applied stress [20]. The growing crack reduces the strength of the ceramic component, leading to failure at stress levels much lower than those necessary to cause fracture under inert conditions [33]. The effect of wet cyclic loading has been experimentally demonstrated $[22,23,25]$ and was also observed in our study, in which, the failure loads were reduced to $37 \%$ and $53 \%$ of the monotonic loads (Table 1), for crowns with $50 \mu \mathrm{m}$ and $500 \mu \mathrm{m}$ of occlusal cement thickness, respectively. These much lower means under wetcyclic failure loads could be explained simply based on time under stress or on additional damage mechanisms, such as damage accumulation, de-bonding, cement degradation [23].
The results showed a smaller reduction in the wet cyclic failure load for $500 \mu \mathrm{m}$-thick-cement than for $50 \mu \mathrm{m}$ (Table 1; Fig. 5). According to Feilzer et al. [16], water sorption can relieve the stresses generated by polymerization in hydrophilic composite and its sorption can actually surpass the neutral condition and could be responsible for some expansion stress in the adhesive interface. This phenomenon could have been responsible for reduction of gaps caused by the polymerization shrinkage during cementation. This may have relieved some tensile-stress at the ceramic surface, reducing the influence of the occlusal cement layer on the crown failure loads when the environment is wet and the cement is thicker. The percentage of hygroscopic expansion is dependent on the volume and the immersion time [17]. Probably the water sorption and expansion was incomplete, especially for $500 \mu \mathrm{m}$ samples, given that the immersion time before testing was $96 \mathrm{~h}$, while for $2 \mathrm{~mm}$ thick composite samples, hygroscopic expansion equilibrium was achieved by 60 days [18]. Since all specimens experienced the same water exposure times and the main variable being studied was cement thickness, the relative results are acceptable.

Even considering a possible partial compensation of the tensile stresses by water sorption, crowns under wet cyclic loading cemented with $500 \mu \mathrm{m}$ proved less resistant than those cemented with $50 \mu \mathrm{m}(p<0.001)$. It has been recommended, based on monotonic testing conditions, that the occlusal cement thickness under feldspathic CAD/CAM crowns should be limited to $100 \mu \mathrm{m}$ [15]. Investigation using intermediate values between 50 and $500 \mu \mathrm{m}$ would be useful in identifying the critical value for the occlusal cement thickness when the crowns are submitted to wet fatigue. In face of the current results we can recommend that technicians and dentists must pay attention to the occusal misfit resulting from the machining of ceramic crowns, since the occlusal cement thickness should be as thin as possible in order to minimize the consequences in terms of resistance of the ceramic crowns. This recommendation is limited to resin-based cements and may not hold for acid-base cements.

\section{Conclusions}

Mean failure loads are influenced by the occlusal resinbased cement thickness. Fatigue failure loads for crowns with $500 \mu \mathrm{m}$ of occlusal cement thickness were lower than those for crowns with $50 \mu \mathrm{m}$.

The wet cyclic load testing reduced the failure loads of CAD/CAM ceramic crowns in comparison to dry monotonic testing for both occlusal cement thickness. This effect was less pronounced for the thicker cement thickness.

The occlusal cement thickness of $50 \mu \mathrm{m}$ is more favorable for the structural performance of feldspathic crowns.

\section{REF E RE N C E S}

[1] Proos KA, Swain MV, Ironside J, Steven GP. Influence of cement on a restored crown of a first premolar. Int $J$ Prosthodont 2003;16(1):82-90. 
[2] Rekow ED, Harsono M, Janal M, Thompson VP, Zhang G. Factorial analysis of variables influencing stress in all-ceramic crowns. Dent Mater 2006;22:125-32.

[3] Scherrer SS, Rijk WG, Belser UC, Meyer J. Effect of cement film thickness on the fracture resistance of a machinable glass-ceramic. Dent Mater 1994;10:172-7.

[4] Colpani JT, Borba M, Della Bona A. Evaluation of marginal and internal fit of ceramic crown copings. Dent Mater 2013;2(9):174-80.

[5] Boening KW, Wolf BH, Schmidt AE, Kästner K, Walter MH. Clinical fit of Procera AllCeram crowns. J Prosthet Dent 2000;84:419-24

[6] Kokubo Y, Ohkubo C, Tsumita M, Miashita A, Vult von Steyern P, Fukushima S. Clinical marginal and internal gaps of Procera AllCeram crowns. J Oral Rehabil 2005;32:526-30.

[7] Nakamura T, Tanaka H, Kinuta S, Akao T, Okamoto K, Wakabayashi $\mathrm{K}$, et al. In vitro study on marginal and internal fit of CAD/CAM All-ceramic crowns. Dent Mater J 2005;24:456-9.

[8] Kunii J, Hotta Y, Tamaki Y, Ozawa A, Kobayashi Y, Fujishima A, et al. Effect of sintering on the marginal and internal fit of CAD/CAM-fabricated zirconia frameworks. Dent Mater J 2007;26:820-6.

[9] Martins LM, Lorenzoni FC, Melo AO, Silva LM, Oliveira JLG, Oliveira PCG, et al. Internal fit of two all-ceramic systems and metal-ceramic crowns. J Appl Oral Sci 2012;20(2):235-40.

[10] Brawek PK, Wolfart S, Endres L, Kirsten A, Reich S. The clinical accuracy of single crowns exclusively fabricated by digital workflow-the comparison of two systems. Clin Oral Invest 2013;17:2119-25.

[11] Miura S, Inagaki R, Kasahara S, Yoda M. Fit of zirconia all-ceramic crowns with different cervical margin designs, before and after porcelain firing and glazing. Dent Mater J 2014;33(4):484-9.

[12] Akin A, Toksavul S, Toman M. Clinical marginal and internal adaptation of maxillary anterior single all-ceramic crowns and 2-year randomized controlled clinical trial. J

Prosthodont 2014, http://dx.doi.org/10.1111/jopr.12217.

[13] Lin MT, Muñoz JS, Muñoz CA, Goodacre CJ, Naylor WP. The effect of tooth preparation form on the fit of Procera copings. Int J Prosthodont 1998;11:580-90.

[14] Luthardt RG, Bornemann G, Lemelson S, Walter MH, Hüls A. An innovative method for evaluation of the 3-D internal fit of CAD/CAM crowns fabricated after direct optical versus indirect laser scan digitizing. Int J Prosthodont 2004;17:680-5.

[15] May LG, Kelly JR, Bottino MA, Hill T. Effects of cement thickness and bonding on the failure loads of CAD/CAM ceramic crowns: multi-physics FEA modeling and monotonic testing. Dent Mater 2012;28(8):e99-109.

[16] Feilzer AJ, De Gee AJ, Davidson CL. Relaxation of polymerization contraction shear stress by hygroscopic expansion. J Dent Res 1990;69(1):36-9.
[17] Feilzer AJ, De Gee AJ, Davidson CL. Increased wall-to-wall curing contraction in thin bonded resin layers. J Dent Res 1989;68(1):48-50.

[18] Alrahlah A, Silikas N, Watts DC. Hygroscopic expansion kinetics of dentalresin-composites. Dental Mater 2014;30:143-8.

[19] Suresh S. Fatigue of materials. 2nd ed. Cambridge: University Press; 1998. p. 679.

[20] Michalsky Freiman. A molecular mechanism for stress-corrosion in vitreous silica. J Am Ceram Soc 1983;66:284-8.

[21] Taskonak B, Griggs JA, Mecholsky Jr JJ, Yan J-H. Analysis of subcritical crack growth in dental ceramics using fracture mechanics and fractography. Dental Mater 2008;24: 700-7.

[22] Attia A, Abdelaziz KM, Freitag S, Kern M. Fracture load of composite resin and feldsphatic all-ceramic CAD/CAM crowns. J Prosthet Dent 2006;95:117-23.

[23] Kelly JR, Rungruanganunt P, Hunter B, Vailati F. Development of a clinically-validated bulk failure test for ceramic crowns. J Prosthet Dent 2010;104:228-38.

[24] Collins JA. Staircase or up-and-down methods. In: Failure of materials in mechanical design. New York: John Wiley \& Sons; 1981. p. 369-74.

[25] Silva NRFA, Souza GM, Coelho PG, Stappert CFJ, Clark EA, Rekow ED, et al. Effect of water storage time and composite cement thickness on fatigue of a glass-ceramic trilayer system. J Biomed Mater Res Part B: Appl Biomater 2008;84B:117-23.

[26] Binmahfooz AM, Nathanson, D. Effect of photocuring vs autocuring on properties of resin cements. In: IADR 86th General Session \& Exhibition, 2007 July 3-5, 2008. Toronto [abstract 0982].

[27] Fischer H, Dautzenberg G, Marx R. Nondestructive estimation of the strength of dental ceramic materials. Dent Mater 2001;17:289-95.

[28] Hsueh C-H, Kim JH, Kim DK. Modeling of effects of adhesive interlayers on contact-induced radial cracking in brittle coatings on substrates. J Mater Res 2003;18:1481-6.

[29] Tuntiprawon M, Wilson PR. The effect of cement thickness on the fracture strength of all-ceramic crowns. Aust Dent 1995;40(1):17-21.

[30] Kelly JR. Clinically relevant approach to failure testing of all-ceramic restorations. J Prosthet Dent 1999;81(6): 652-61.

[31] Dixon WJ, Mood AM. A method for obtaining and analyzing sensitivity data. J Am Statistical Assoc 1948;43:109-26.

[32] Danzer R, Tanja Lube T, Peter Supancic P, Danzer RD. Fracture of ceramics. Ad Eng Mater 2008;10(4):275-98.

[33] Studart AR, Filser F, Kocher P, Gaukler LJ. In vitro lifetime of dental ceramics under cyclic loading in water. Biomaterials 2007;28:2695-705 